\title{
Thermal Stability of Low-Resistance Au Ohmic Contacts to GeTe
}

Haila M. Aldosari, Kayla A. Cooley, Shih-Ying Yu, Katherine C. Kragh-Buetow and Suzanne E. Mohney

Department of Materials Science and Engineering and Materials Research Institute, The Pennsylvania State University, University Park, Pennsylvania 16802, USA

\begin{abstract}
Low-resistance Ohmic contacts for phase change materials (PCMs) such as GeTe are required for devices such as radio frequency switches. The contacts must also exhibit good thermal stability since the PCM is switched by heating. In this work, Au Ohmic contacts to GeTe have been examined, including the effect of pre-metallization surface preparation and annealing on the resistance of the contacts. Although some form of premetallization surface treatment must be performed after photolithography to produce contacts with low resistance, the contact resistance $\left(\mathrm{R}_{\mathrm{c}}\right)$ and specific contact resistance $\left(\rho_{c}\right)$ were insensitive to the pre-metallization surface treatment chosen, whether in-situ $\mathrm{Ar}^{+}$plasma treatment was used, or $\mathrm{UV}-\mathrm{O}_{3}$ treatments followed by immersion in deionized $\mathrm{H}_{2} \mathrm{O},\left(\mathrm{NH}_{4}\right)_{2} \mathrm{~S}$, or $\mathrm{HCl}$. In all cases, $\mathrm{R}_{\mathrm{c}}$ was $0.007 \pm 0.001 \Omega$.mm and $\rho_{\mathrm{c}}$ was $1.2-1.3 \times 10^{-8}$ $\Omega . \mathrm{cm}^{2}$. Thermal stability was also investigated at 250,300 , and $350{ }^{\circ} \mathrm{C}$ for $30 \mathrm{~min}$. The contact resistance increased as annealing temperature increased, and changes in the contacts were observed using field emission scanning electron microscopy, transmission electron microscopy, and energy dispersive spectroscopy. No solid-state reaction
\end{abstract}


occurred between $\mathrm{Au}$ and GeTe, even at $350{ }^{\circ} \mathrm{C}$. Rather, the increase in resistance could be attributed to slit-like defects that appeared and grew in the Au layer, through which sublimation of Te occurred.

\section{Keywords:}

GeTe, phase change material (PCM), Ohmic contact

\section{Introduction}

Phase change materials (PCMs), including GeTe, are currently of interest for radio frequency $(\mathrm{RF})$ switches. However, the contact resistance $\left(\mathrm{R}_{\mathrm{c}}\right)$ contributes significantly to the ON-state resistance of the RF switches, impacting their performance [1]. A contact that can withstand heating is desirable due to the use of heat in switching the PCMsbased RF switches ON and OFF. However, few authors have described Ohmic contacts to crystalline GeTe $[1,2]$, and information about their thermal stability is scant. Chua et al.[2] used in-situ $\mathrm{Ar}^{+}$plasma pre-cleaning followed by deposition of $50 \mathrm{~nm} \mathrm{Ni}, \mathrm{W}$, or TiW contacts, capped with $150 \mathrm{~nm} \mathrm{Al}$, as contacts to both crystalline and amorphous GeTe identifying Ni contacts as having the lowest resistance, while King et al. [1] used $\mathrm{Ti} / \mathrm{Au}$ contacts.

In this work, we studied $\mathrm{Au}(100 \mathrm{~nm})$ Ohmic contacts to GeTe. We chose $\mathrm{Au}$ since it has been reported to be in thermodynamic equilibrium with GeTe on the condensed phase diagram [3], although we must keep in mind that the Au-Ge system has a low eutectic temperature of $361{ }^{\circ} \mathrm{C}$ [4]. Additionally, Au has a high work function of 
$5.1 \mathrm{eV}$ [5], and might therefore be expected to provide low contact resistance on p-type GeTe. Finally, an elemental contact is easier to fabricate compared to alloyed or layered contacts. We therefore describe the preparation of $\mathrm{Au}$ contacts to GeTe, including the role of pre-metallization surface preparation on the as-deposited contact resistance, and the impact of annealing. Field emission scanning electron microscopy (SEM), crosssectional transmission electron microscopy (TEM), and energy dispersive spectroscopy (EDS) were used to characterize the contacts, allowing us to understand the limitations on the thermal stability of $\mathrm{Au} / \mathrm{GeTe}$ contacts.

\section{Experimental Procedures}

Polycrystalline p-type $\alpha$-GeTe with a high hole concentration $\left(\sim 10^{20} \mathrm{~cm}^{-3}\right)$ and a thickness of $110 \mathrm{~nm}$ was sputtered on a Si substrate with a $100 \mathrm{~nm}$ thick amorphous $\mathrm{Si}_{3} \mathrm{~N}_{4}$ barrier layer for this study [1]. The sheet resistance of GeTe films was $44 \Omega . \square^{-1}$. For electrical measurements, "refined" transfer length method (RTLM) test structures [6] (Fig. 1) were patterned with nominal gap spacings of 0.6-2 $\mu \mathrm{m}$. Square 1 x $1 \mathrm{~cm}$ samples were degreased in acetone, isopropanol, and deionized (DI) water for 5 min each with ultrasonication for $10 \mathrm{~s}$ each and then blown dry with $\mathrm{N}_{2}$. Then, samples were baked in air for $3 \mathrm{~min}$ at $115{ }^{\circ} \mathrm{C}$ to remove moisture. RTLM structures were fabricated by spin coating the sample with a dual-layer lift-off resist stack of polymethyl methacrylate 950/SPR3012 followed by I line optical exposure, $1^{\text {st }}$ stage development using CD-26 (tetramethylammoniumhydroxide/TMAH), $\mathrm{O}_{2}$ plasma ashing, deep UV flood exposure, and $2^{\text {nd }}$ stage development using toluene. 
After patterning, the subset of samples that were to be treated later with wet chemicals were oxidized inside a PR-100 UV-Ozone Photoreactor (UVP Inc., San Gabriel, CA) for $10 \mathrm{~min}$ at 1 SLPM to remove organic contaminants [7], although the treatment does cause oxide to grow on the surface. Afterwards, the samples were treated with ammonium sulfide $\left(\left(\mathrm{NH}_{4}\right)_{2} \mathrm{~S}\right)$, hydrochloric acid $(\mathrm{HCl})$, or DI water with the intent of removing oxide from the surface of the GeTe. For $\left(\mathrm{NH}_{4}\right) \mathrm{S}_{2}$ treated samples, a dilution of (100:1) $\mathrm{H}_{2} \mathrm{O}: 22-24 \%\left(\mathrm{NH}_{4}\right) \mathrm{S}_{2}$ was used for $30 \mathrm{~s}$. For $\mathrm{HCl}$ treated samples, a dilution of (10:1) $\mathrm{H}_{2} \mathrm{O}: 37 \% \mathrm{HCl}$ was used for $120 \mathrm{~s}$. After each treatment, the sample was rinsed with DI water for $15 \mathrm{~s}$ and blown dry with $\mathrm{N}_{2}$. When DI water treatment was the treatment, it was used for $5 \mathrm{~min}$. Although DI water alone is not usually employed as a premetallization surface treatment for other semiconductors, for GeTe it is beneficial due to the solubility of $\mathrm{GeO}_{2}$ in water [8]. As an alternative, in-situ $\mathrm{Ar}^{+}$ion etching was conducted on samples that were not exposed to $\mathrm{UV}_{-} \mathrm{O}_{3}$ treatment. $\mathrm{The} \mathrm{Ar}^{+}$ions are able to remove both organic contamination and oxide. Surface preparation procedures used in the work are summarized in Table 1.

Afterwards, samples were loaded into an e-beam evaporation system with base pressure $<2.6 \times 10^{-5} \mathrm{~Pa}$. Then, $100 \mathrm{~nm}$ of $\mathrm{Au}$ was deposited. For $\mathrm{Ar}^{+}$plasma treatment, an in-situ $\mathrm{Ar}^{+}$plasma was used in the deposition chamber with an $\mathrm{Ar}$ flow rate of $10 \mathrm{sccm}$ and power of $375 \mathrm{~W}$ at a pressure of $4 \times 10^{-2} \mathrm{~Pa}$ for $120 \mathrm{~s}$. Also, the $\mathrm{Ar}^{+}$plasma treated samples were subjected to cooling at $5{ }^{\circ} \mathrm{C}$ after depositing $\sim 10 \mathrm{~nm} \mathrm{Au}$, to maintain the ability to perform liftoff of the pattern. After contact deposition and liftoff, a $2^{\text {nd }}$ stage of lithography was used to define mesas, and then dry etching was performed to isolate the 
GeTe mesas using $\mathrm{Cl}_{2}$ plasma for $17 \mathrm{~s}$ in a Plasmatherm Versalock 700 system. The final mesa edges are $\sim 0.5 \mu \mathrm{m}$ wider than the metal pads on either side.

Four probes were used to measure resistances before and after annealing using a Keithley 237 parameter analyzer with linear current sweep and voltage measurement. Each $R_{c}$ value reported in this work is the mean from at least four different RTLM sets. The reported error values are the standard deviations calculated from those four values.

For the annealing study, a $\mathrm{SiO}_{2}$ capping layer $(10 \mathrm{~nm})$ was electron-beam evaporated to suppress evaporation of Te. Samples were then annealed in a tube furnace in flowing Ar. Thermal stability was examined by annealing samples at three different temperatures $\left(250,300\right.$, and $350{ }^{\circ} \mathrm{C}$ ) for $30 \mathrm{~min}$ in Ar flowing at $0.1 \mathrm{~mL} / \mathrm{min}$ in an Applied Test Systems, Inc. (ATS) furnace. Adding the $\mathrm{SiO}_{2}$ cap did not change the resistance of the contacts before annealing, and it was easy to probe the contacts through the thin cap.

After electrical characterization, gap spacings and mesa widths were measured via scanning electron microscopy (SEM). Surface EDS were captured using Aztec software (Version 3.1) in a FEI NanoSEM 630 FESEM. Afterwards, cross-sections from the metal/semiconductor edge were prepared in an FEI Quanta 3D 200 FIB for crosssectional transmission electron microscopy. This sample preparation procedure included depositing a protective layer of $\mathrm{C}(1 \mu \mathrm{m}$ thick $)$ via ion-beam gas-assisted chemical vapor deposition. Bright fieldand high angle annular dark field (HAADF) scanning TEM (STEM) micrographs were taken in a FEI Talos transmission electron microscope using 
an accelerating voltage of $200 \mathrm{kV}$. Moreover, energy dispersive spectroscopy (EDS) was performed with a built-in Super X-EDS system for elemental analysis.

\section{Results and Discussion}

Fig. 2a (b) shows measured $R_{c}\left(\rho_{c}\right)$ of $100 \mathrm{~nm} \mathrm{Au}$ contacts to GeTe as a function of various pre-metallization surface preparation procedures. The surface treatments barely changed the contact resistance $\left(\mathrm{R}_{\mathrm{c}}\right)$ or specific contact resistance $\left(\rho_{\mathrm{c}}\right)$ of the $\mathrm{Au}$ contacts. The constant $\mathrm{R}_{\mathrm{c}}$ for different surface preparations might be attributed to the lack of reactivity of Au with GeTe considering that we have observed a marked difference in the case of a reactive metal (nickel), which was correlated with the Ge:Te ratio after treatment [9]. A summary of the extracted data (contact resistance, specific contact resistance, semiconductor sheet resistance $\left(\mathrm{R}_{\text {sh }}\right)$, and transfer length $\left(\mathrm{L}_{t}\right)$ ) from currentvoltage (I-V) measurements for the as-deposited Au contacts is provided in Table 2. In order to extract $\rho_{c}$, the sheet resistance of GeTe between and under the contacts was assumed to be the same.

Figs. 3a-b show a HAADF STEM image of the cross-section of as-deposited $\mathrm{Ar}^{+}$ plasma-treated Au contact with nominal thickness of $100 \mathrm{~nm}$ with measured $\mathrm{R}_{\mathrm{c}}=0.007 \pm$ $0.001 \Omega . \mathrm{mm}$. No reaction between Au and GeTe is observed, as confirmed by EDS and the micrographs showing a sharp interface between $\mathrm{Au}$ and GeTe. The low contact resistance is not surprising for contacts to degenerately doped $\mathrm{p}^{+} \mathrm{GeTe}$, similar to that observed using other metals such as $\mathrm{Ni}$ [9], but in this case the metal does not react to form new germanides or tellurides on GeTe when annealed. 
The effect of annealing was investigated for the in-situ $\mathrm{Ar}^{+}$plasma treated samples at three different annealing temperatures $\left(250,300\right.$, and $\left.350{ }^{\circ} \mathrm{C}\right)$ for $30 \mathrm{~min}$. A capping layer of $10 \mathrm{~nm} \mathrm{SiO}{ }_{2}$ was added to preserve the channel integrity during annealing. The $\mathrm{R}_{\mathrm{c}}$ and $\rho_{c}$ of the Au contacts increased slightly after annealing, as shown in Fig. 4. This increase in the contact resistance upon annealing might be attributed to morphological changes and defect formation in the Au layer during annealing, as will be discussed later. The sheet resistance $\left(\mathrm{R}_{\mathrm{sh}}\right)$ values extracted for all contacts were fairly constant after annealing, indicating that the $\mathrm{R}_{\mathrm{sh}}$ between the contacts did not change much with annealing. The results are summarized in Table 3 .

Inspecting the $\mathrm{Au}$ contacts using SEM before and after annealing revealed significant changes in the Au film. The SEM images in Fig. 5 show the effect of annealing temperature on the Au layer. Defects appear in the Au metallization layer and grow in size as the annealing temperature increases. These defects have a slit-like structure with size depending strongly on the annealing temperature. Based on microscopy described below, the defects likely allow sublimation of Te from beneath the contact during annealing. Fig. 6 shows energy dispersive spectroscopy (EDS) maps of the $\mathrm{Au}$ surface after annealing at $350{ }^{\circ} \mathrm{C}$ for 30 min revealing that the slit-like defects are regions where $\mathrm{Au}$ is absent. Wavelengths used for preparing the maps included the $\mathrm{M} \alpha$ line for $\mathrm{Au}$, and the $\mathrm{L} \alpha$ lines for $\mathrm{Ge}$ and $\mathrm{Te}$.

In order to further elucidate the impact of annealing on the Au contacts, crosssectional TEM and EDS were used to investigate the morphological and chemical changes after annealing. For the $\mathrm{Ar}^{+}$plasma-treated $\mathrm{GeTe}$, the $(100 \mathrm{~nm}) \mathrm{Au}$ contact 
annealed at $350{ }^{\circ} \mathrm{C}$ for $30 \mathrm{~min}$, the measured $\mathrm{R}_{\mathrm{c}}=0.013 \pm 0.001 \Omega . \mathrm{mm}$ (Fig. $7 \mathrm{a}-\mathrm{b}$ ). A representative HAADF STEM images (Fig. 7a-b) of the cross-section shows no solidstate reaction between $\mathrm{Au}$ and $\mathrm{GeTe}$ as a result of annealing, with a sharp interface maintained between Au and GeTe. Additionally, the EDS map of the cross-section in Fig. 7c support the lack of reaction between Au and GeTe upon annealing. However, voids formed in both the GeTe film, especially beneath the slit-like openings in the Au films.

Figures 8a and 8b show the HAADF STEM image and EDS map, respectively, of the slit-like defect seen earlier in Fig. 6, revealing outdiffusion of Te (Fig. 8c) through the defect, presumably because of the driving force for its sublimation. These defects might be the reason behind the slight increase in the contact resistance with annealing.

\section{Summary and Conclusions}

The authors report low contact resistance values for $100 \mathrm{~nm}$ Au contacts to GeTe. RTLM test structures were used to examine the influence of various pre-metallization surface preparation procedures and annealing on the contact resistance. Surface preparations including in-situ $\mathrm{Ar}^{+}$plasma treatment and $\mathrm{UV}-\mathrm{O}_{3}$ treatments followed by immersion in DI $\mathrm{H}_{2} \mathrm{O},\left(\mathrm{NH}_{4}\right)_{2} \mathrm{~S}$, and $\mathrm{HCl}$ were examined. The lack of reactivity of $\mathrm{Au}$ with the GeTe yielded the same contact resistance $(0.007 \pm 0.001 \Omega . \mathrm{mm})$ regardless of the surface treatment used prior to metallization. No reaction of Au with GeTe occurred at room temperature and after annealing, consistent with our expectations based on the condensed phase diagram. A sharp interface was maintained even after a severe annealing condition of $350{ }^{\circ} \mathrm{C}$ for $30 \mathrm{~min}$. However, the contact resistance values slightly 
degraded after annealing. This increase in contact resistance was correlated with slit-like openings that appeared in the Au metal layer in which Te was found. Voids were also found in the GeTe film in such regions, indicating loss of atoms from the GeTe layer. Considering the location of Te in the slit in the Au film above the original GeTe layer, the reason for the degradation of the contacts must be sublimation of Te due to its high vapor pressure. It is possible that better protection of the contacts from the environment (a thicker cap) would yield excellent thermal stability.

\section{Acknowledgments}

The authors would like to thank ONR (Dr. Brian Bennett) for support through N00014-15-12395. The authors are grateful to Northrop Grumman Corporation for providing GeTe layers and their helpful discussions. Haila M. Aldosari thanks UAE University TA Scholarship Program for graduate fellowship support.

\section{References}

[1] M.R. King, B.P. Wagner, E.B. Jones, N. El-Hinnawy, P. Borodulin, S.R. McLaughlin, J.S. Mason, R.S. Howell, M.J. Lee, R.M. Young, Development of cap-free sputtered GeTe films for inline phase change switch based RF circuits, J. Vac. Sci. Technol. B, 32 (2014) 041204.

[2] E.K. Chua, R. Zhao, L.P. Shi, T.C. Chong, E. Schlesinger, J.A. Bain, Effect of metals and annealing on specific contact resistivity of GeTe metal contacts, Appl. Phys. Lett., 101 (2012) 012107.

[3] A. Prince, G.V. Raynor, D.S. Evans, Phase Diagrams Ternary Gold Alloys, Institute Of Metals, London, 1990. 
[4] V. Dutta, P. Nath, V.D. Vankar, K.L. Chopra, Structural properties of polycrystalline Gemetal films, Phys. Stat. Sol. (a), 49 (1978) 379.

[5] H.B. Michaelson, The work function of the elements and its periodicity, J. Appl. Phys., 48 (1977) 4729.

[6] R. Dormaier, S.E. Mohney, Factors controlling the resistance of Ohmic contacts to n-InGaAs, J. Vac. Sci. Technol. B, 30 (2012) 031209.

[7] J.R. Vig, UV/ozone Cleaning of Surfaces, J. Vac. Sci. Technol. A, 3 (1985) 1027.

[8] B. Onsia, M. Caymax, T. Conard, S. De Gendt, F. De Smedt, A. Delabie, C. Gottschalk, M.M. Heyns, M. Green, S. Lin, P.W. Mertens, W. Tsai, C. Vinckier, A Study of the Influence of Typical Wet Chemical Treatments on the Germanium Wafer Surface, Solid State Phenom., 103104 (2005) 19.

[9] H.M. Aldosari, Factors Controlling the Contact Resistance of Ohmic Contacts to Germanium Telluride Materials Science and Enginering, The Pennsylvania State University, Ph.D. Thesis, University Park, PA (2016). 


\section{List of figure and table captions}

Table 1. Summary of surface preparation procedures used in this study.

Table 2. Summary of the extracted data from current-voltage measurements for the asdeposited $\mathrm{Au}$ contacts as a function of different pre-metallization surface preparation procedures.

Table 3. Summary of the extracted data from I-V measurements for the $\mathrm{Ar}^{+}$plasmatreated Au contacts as a function annealing.

Fig.1. SEM micrograph of RTLM test structure used in this study.

Fig. 2. Dependence of (a) $R_{c}$ and (b) $\rho_{c}$ on surface preparation procedures prior to metallization of $100 \mathrm{~nm}$ Au contacts to GeTe.

Fig. 3. (a) Low and (b) high magnification HAADF STEM images of the as-deposited $\mathrm{Ar}^{+}$plasma-treated $\mathrm{Au}(100 \mathrm{~nm})$ contacts. (c) EDS map of as-deposited $\mathrm{Ar}^{+}$plasmatreated $\mathrm{Au}(100 \mathrm{~nm})$.

Fig. 4. (a) $\mathrm{R}_{\mathrm{c}}$ and (b) $\rho_{\mathrm{c}}$ of $\mathrm{Ar}^{+}$plasma-treated $\mathrm{Au}$ contacts to GeTe as a function of annealing temperature.

Fig. 5. SEM images of the Au film surface before and after annealing, showing defects formation in the Au layer upon annealing at each temperature. 
Fig. 6. EDS maps of the Au surface of the $350{ }^{\circ} \mathrm{C}$ annealed sample, revealing an absence of $\mathrm{Au}$ in the defects in the film.

Fig. 7. (a) Low and (b) high magnification HAADF STEM images of the $\mathrm{Ar}^{+}$plasmatreated $\mathrm{Au}(100 \mathrm{~nm})$ annealed at $350{ }^{\circ} \mathrm{C}$ for 30 min capped with $10 \mathrm{~nm}$ of $\mathrm{SiO}_{2}$. (c) EDS map of $\mathrm{Ar}^{+}$plasma-treated $\mathrm{Au}(100 \mathrm{~nm})$ contact annealed at $350{ }^{\circ} \mathrm{C}$ for $30 \mathrm{~min}$.

Fig. 8. (a) HAADF STEM image and (b) EDS map of $\mathrm{Ar}^{+}$plasma-treated $\mathrm{Au}(100 \mathrm{~nm})$ annealed at $350{ }^{\circ} \mathrm{C}$ for 30 min capped with $10 \mathrm{~nm}$ of $\mathrm{SiO}_{2}$. Individual (c) $\mathrm{Te}$ and (d) Ge EDS elemental maps are shown. 


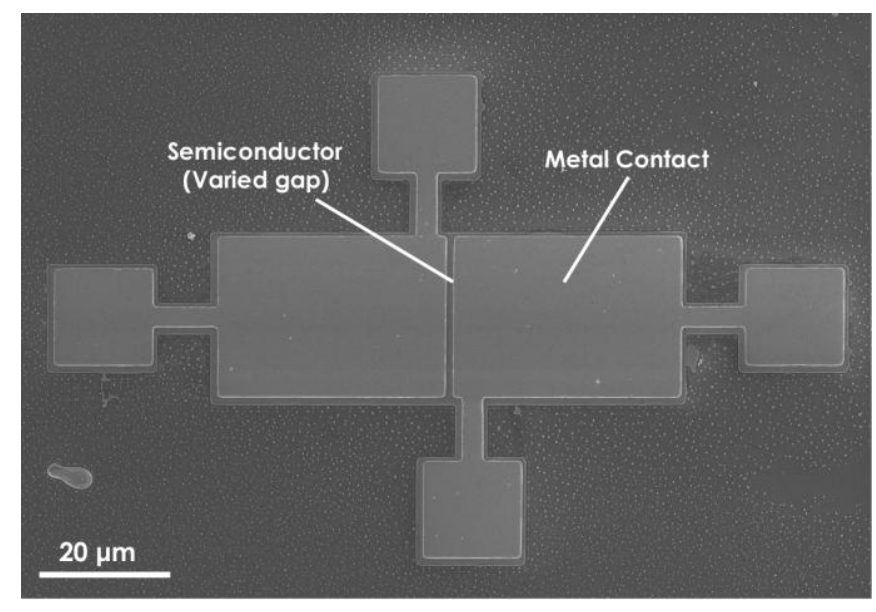


(a)

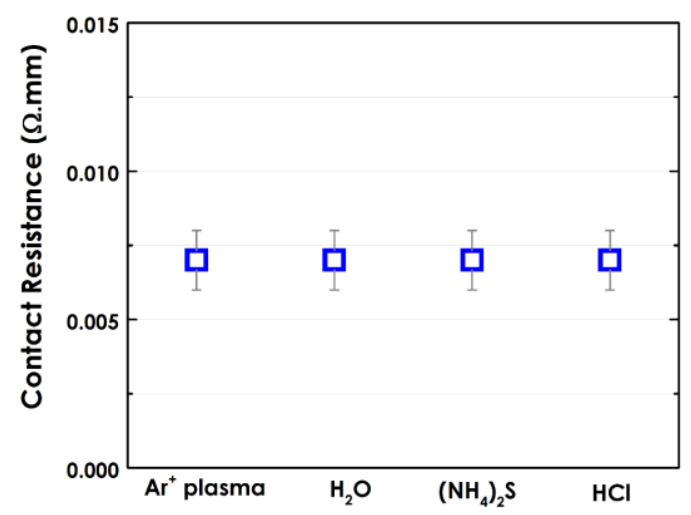

(b)

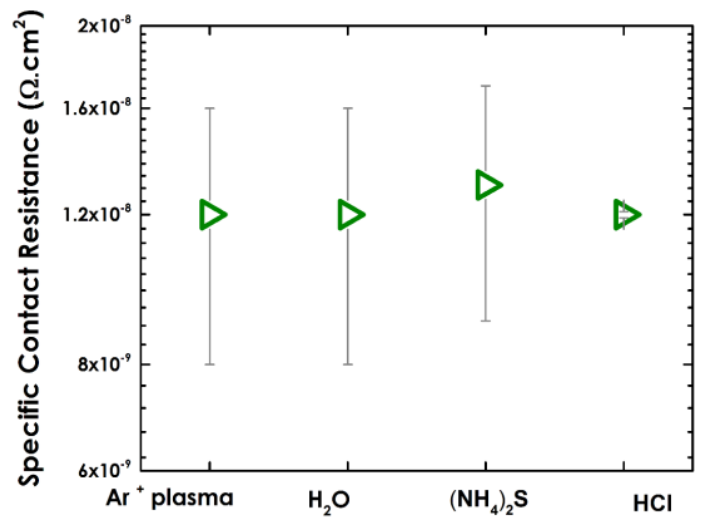


(a)

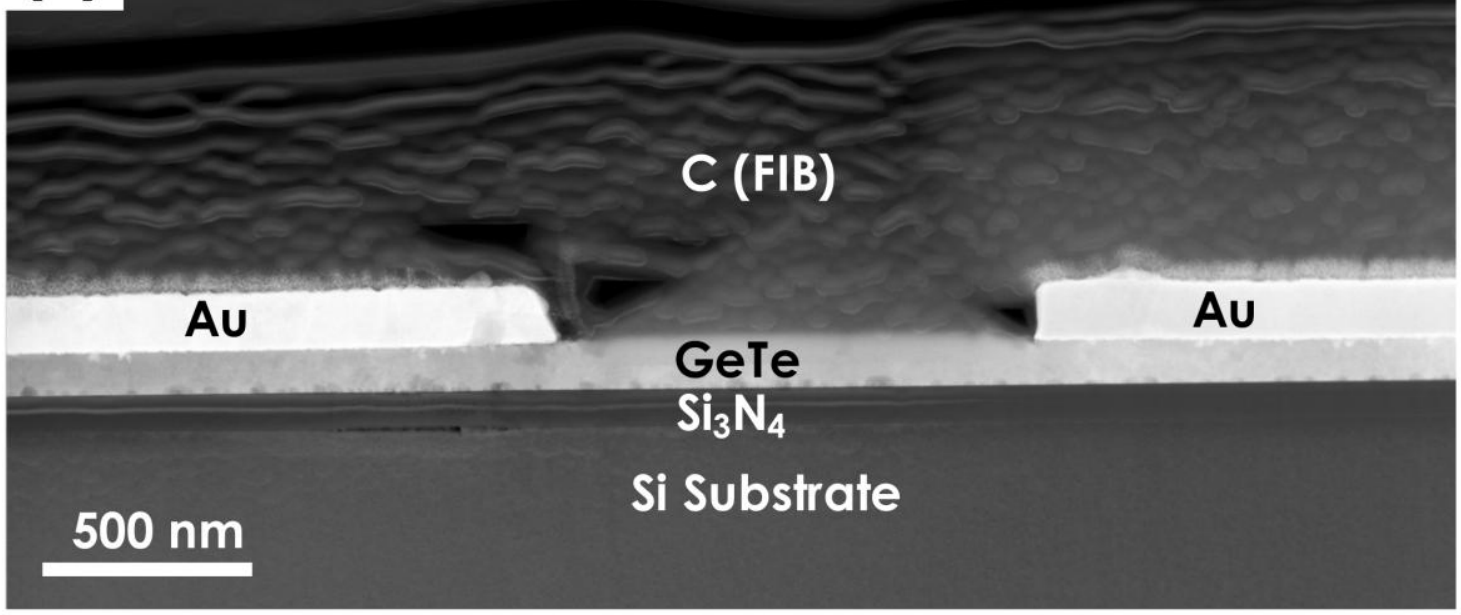

\section{(b)}

Au

GeTe

$\mathrm{Si}_{3} \mathrm{~N}_{4}$

Si Substrate (c)

Au

GeTe

$\mathrm{Si}_{3} \mathrm{~N}_{4}$

Si Substrate

N 0 Si Au Ge Te 
(a)

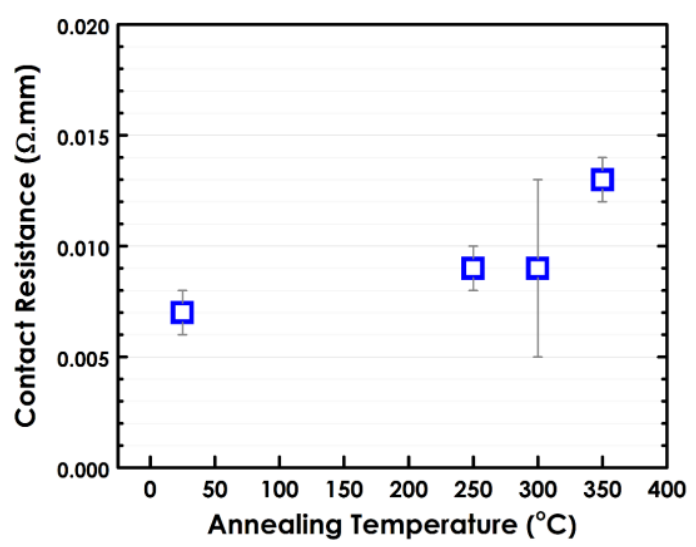

(b)

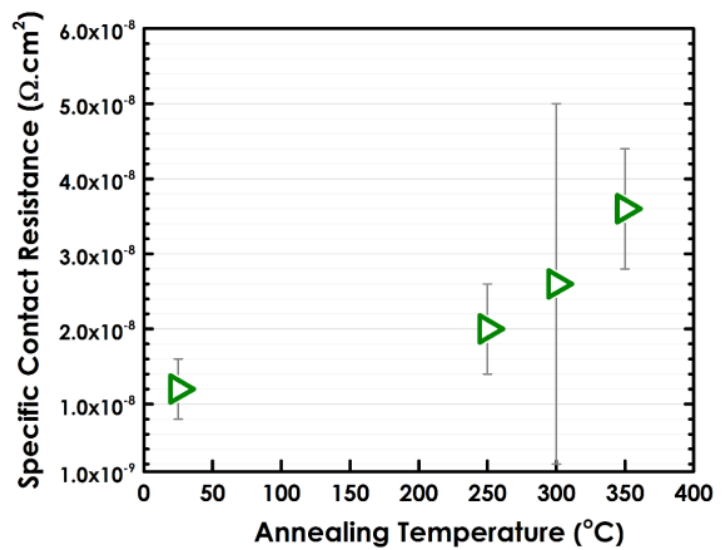




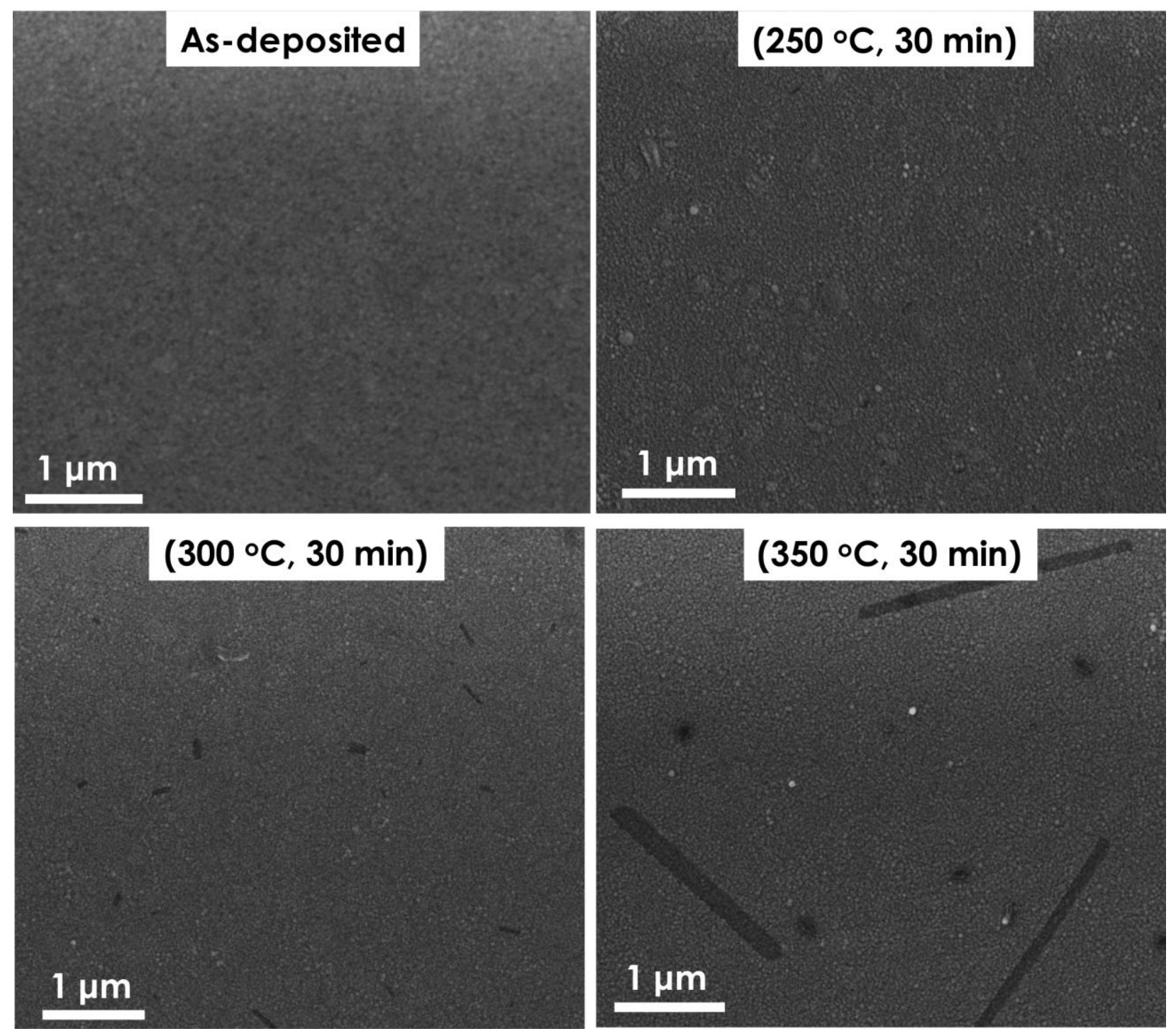



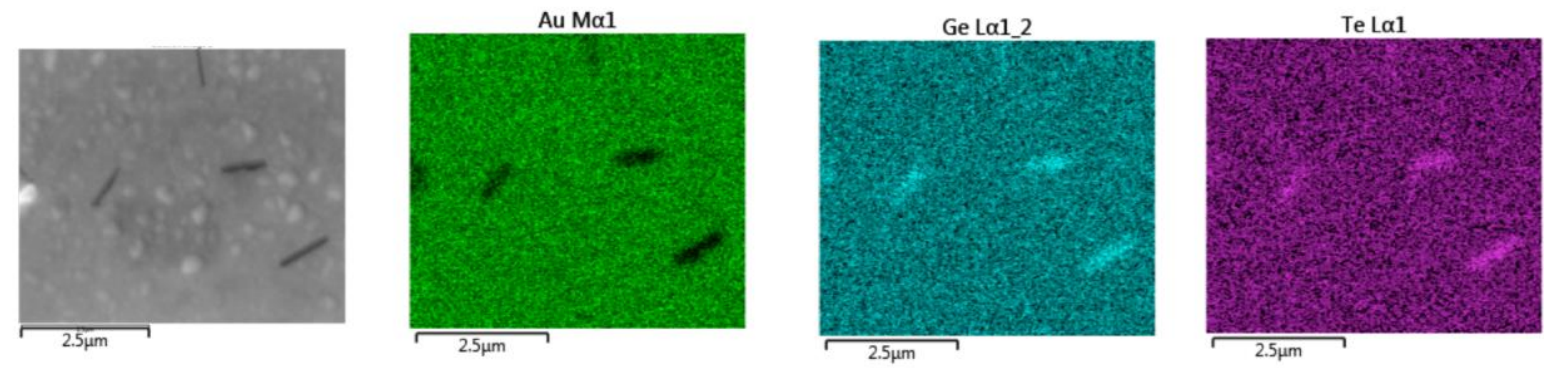

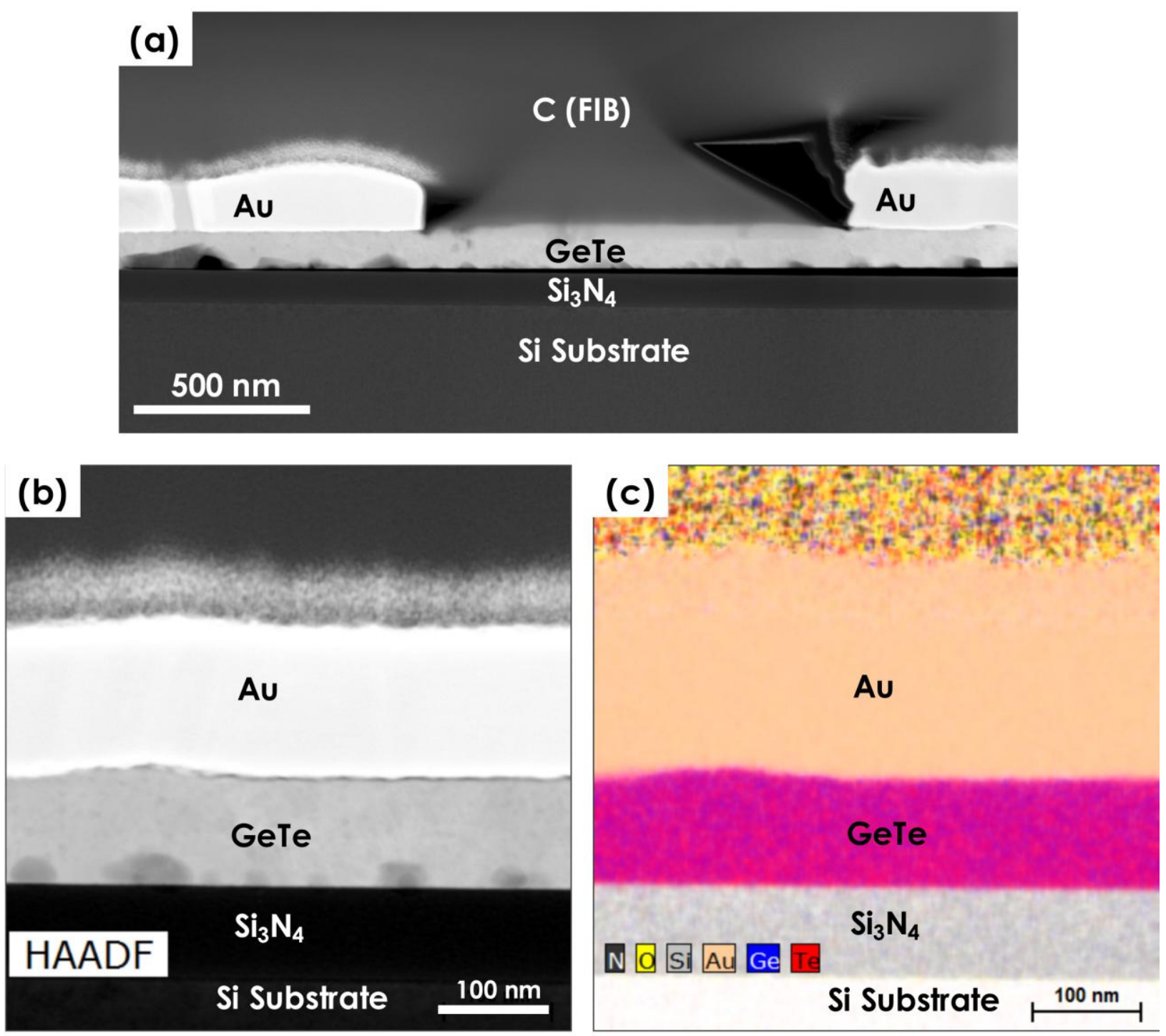


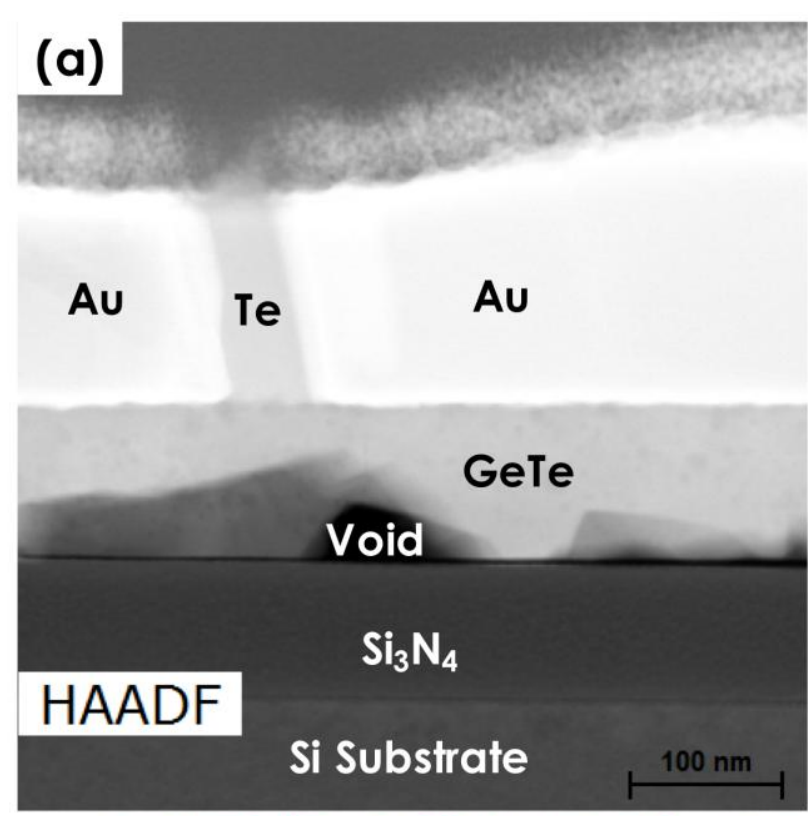

(b)

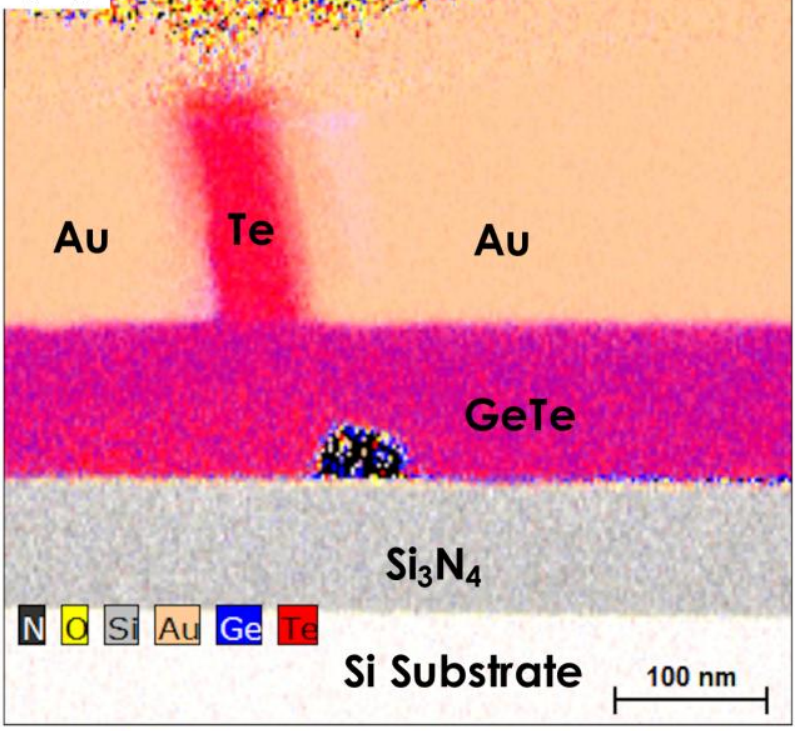

(c)

(d)

$\mathrm{Te}$ 


\begin{tabular}{|l|l|}
\hline & Preparation Details \\
\hline 1 & 5 min $\mathrm{Ar}^{+}$ion etching \\
\hline 2 & 10 min ${\mathrm{UV}-\mathrm{O}_{3}}_{3}$ treatment, 5 min DI water, $\mathrm{N}_{2}$ dry \\
\hline 3 & 10 min ${\mathrm{UV}-\mathrm{O}_{3}}_{3}$ treatment, $\mathrm{H}_{2} \mathrm{O}: \mathrm{HCl}(10: 1) 2$ min, $15 \mathrm{~s}$ DI water rinse, $\mathrm{N}_{2}$ dry \\
\hline 4 & 10 min ${\mathrm{UV}-\mathrm{O}_{3}}_{3}$ treatment, $\mathrm{H}_{2} \mathrm{O}:\left(\mathrm{NH}_{4}\right)_{2} \mathrm{~S}(100: 1) 30 \mathrm{~s}, 15 \mathrm{~s}$ DI water rinse, $\mathrm{N}_{2}$ dry \\
\hline
\end{tabular}




\begin{tabular}{|l|c|c|c|c|}
\hline Surface treatment & $\mathrm{R}_{\mathrm{c}}(\Omega . \mathrm{mm})$ & $\rho_{\mathrm{c}}\left(\Omega . \mathrm{cm}^{2}\right)$ & $\mathrm{R}_{\mathrm{sh}}\left(\Omega . \square^{-1}\right)$ & $\mathrm{L}_{\mathrm{t}}(\mu \mathrm{m})$ \\
\hline $\mathrm{Ar}^{+}$plasma & $0.007 \pm 0.001$ & $1.2 \pm 0.4 \times 10^{-8}$ & $46.2 \pm 0.5$ & $0.15 \pm 0.02$ \\
\hline $\mathrm{H}_{2} \mathrm{O}$ & $0.007 \pm 0.001$ & $1.2 \pm 0.4 \times 10^{-8}$ & $43.0 \pm 1.6$ & $0.17 \pm 0.03$ \\
\hline$\left(\mathrm{NH}_{4}\right)_{2} \mathrm{~S}$ & $0.007 \pm 0.001$ & $1.3 \pm 0.4 \times 10^{-8}$ & $42.6 \pm 1.6$ & $0.17 \pm 0.01$ \\
\hline $\mathrm{HCl}$ & $0.007 \pm 0.001$ & $1.2 \pm 0.1 \times 10^{-8}$ & $44.5 \pm 1.0$ & $0.16 \pm 0.01$ \\
\hline
\end{tabular}




\begin{tabular}{|c|c|c|c|c|}
\hline Annealing temperature $\left({ }^{\circ} \mathrm{C}\right)$ & $\mathrm{R}_{\mathrm{c}}(\Omega . \mathrm{mm})$ & $\rho_{\mathrm{c}}\left(\Omega . \mathrm{cm}^{2}\right)$ & $\mathrm{R}_{\mathrm{sh}}\left(\Omega . \square^{-1}\right)$ & $\mathrm{L}_{\mathrm{t}}(\mu \mathrm{m})$ \\
\hline 250 & $0.009 \pm 0.001$ & $2.0 \pm 0.6 \times 10^{-8}$ & $46.2 \pm 1.7$ & $0.21 \pm 0.03$ \\
\hline 300 & $0.009 \pm 0.004$ & $2.6 \pm 2.4 \times 10^{-8}$ & $42.8 \pm 4.8$ & $0.23 \pm 0.12$ \\
\hline 350 & $0.013 \pm 0.001$ & $3.6 \pm 0.8 \times 10^{-8}$ & $43.8 \pm 1.7$ & $0.29 \pm 0.03$ \\
\hline
\end{tabular}

